https://idp.uoc.edu

ARTÍCULO

\title{
Tributación de las plataformas de financiación participativa no financiera ${ }^{1}$
}

\author{
Montserrat Casanellas Chuecos \\ Universidad de Barcelona
}

Fecha de presentación: diciembre de 2020

Fecha de aceptación: febrero de 2021

Fecha de publicación: octubre de 2021

\section{Resumen}

En el presente trabajo se analiza el régimen jurídico tributario aplicable a las plataformas de financiación participativa que gestionan proyectos que no conllevan ningún tipo de rentabilidad financiera. Ante la ausencia de normativa específica sobre la materia, el estudio se ha realizado partiendo de los dos modelos de gestión que subyacen en el funcionamiento de este tipo de plataformas, así como de la naturaleza jurídica de sus titulares y de las operaciones que llevan a cabo. En este contexto, se analiza la tributación de las plataformas de financiación participativa en el ámbito de la imposición directa e indirecta y se apuntan los principales problemas que la misma plantea con propuestas que, de lege ferenda, pueden ser útiles para una futura regulación de esta materia.

\section{Palabras clave}

plataformas digitales, financiación participativa, crowdfunding no lucrativo, financiación alternativa de proyectos

\footnotetext{
1. Este trabajo se ha realizado en el marco del Proyecto de I+D «Tecnología y fiscalidad en el siglo XXI» (DER2016-8323-P).
} 


\title{
The taxation of non-profit peer-to-peer lending platforms ${ }^{1}$
}

\begin{abstract}
This article analyses the taxation legal framework applicable to the peer-to-peer lending platforms which manage projects that do not involve any kind of financial profitability. Given that there is an absence of specific regulations in this area, the study has been conducted by using as a starting point the two management models underlying the functioning of these kinds of platforms, as well as the functioning of the legal nature of their owners and the operations which they carry out. In this context, an analysis regarding the taxation of peer-to-peer lending platforms in area of direct and indirect taxes is made. The work also includes indications of the main legal problems that these platforms create. Finally, the article concludes with proposals as lex ferenda that may be useful for future regulations in this area.
\end{abstract}

\section{Keywords}

Digital platforms, peer-to-peer lending, non-profit crowdfunding, alternative project funding

1. This work has been carried out within the framework of the R\&D Project "Technology and the taxation system in the 21st century" (DER2016-8323-P). 


\section{Introducción}

La compleja coyuntura económica de los últimos años ha obstaculizado el desarrollo de infinidad de proyectos e iniciativas empresariales de pequeña y mediana dimensión debido a la ingente reducción de las ayudas e inversiones públicas y a las serias dificultades de acceso a las formas tradicionales de financiación. Esta circunstancia, junto con el exponencial desarrollo de las nuevas tecnologías de la sociedad de la información y el crecimiento de los movimientos sociales de implicación comunitaria, han sido elementos clave para el desarrollo de sistemas alternativos de financiación cooperativa ${ }^{2}$ en los que un variado número de personas canalizan sus aportaciones a través de plataformas ubicadas en internet con el fin de coadyuvar en el desarrollo de un determinado proyecto.

En el contexto descrito, la plataforma de financiación participativa es la pieza fundamental que articula las relaciones que se establecen entre los promotores de proyectos y los posibles colaboradores en la financiación de los mismos, en la medida en que crea un entorno o soporte digital de confianza que, en primera instancia, posibilita el nacimiento de dicha colaboración.

La regulación de las plataformas de financiación participativa se incorporó a nuestro ordenamiento jurídico mediante la Ley 5/2015, de 27 de abril, de fomento de la financiación empresarial. Ahora bien, este texto normativo únicamente establece el régimen jurídico aplicable a las plataformas que desarrollan una actividad esencialmente financiera en la medida en que la financiación participativa de los proyectos que promueven se articula sobre operaciones de préstamo o mediante participaciones en el capital de la sociedad que presenta el proyecto, quedando al margen, por expresa disposición legal, las plataformas cuya actividad se centra en la promoción de proyectos que no llevan asociada ninguna rentabilidad financiera. En este sentido, el art. 46.2 del citado texto normativo deja fuera de su ámbito de aplicación a las entidades que gestionan plataformas cuya actividad consiste en la captación de fondos mediante donaciones, venta de bienes y servicios y préstamos sin interés, esto es, las plataformas cuya actividad se centra en el denominado crowdfunding no lucrativo ${ }^{3}$. Son precisamente estas últimas plataformas las que constituyen el objeto de estudio del presente trabajo. Ante la ausencia de norma específica que regule el régimen jurídico y tributario de las mismas, el estudio de su fiscalidad requiere atender a los modelos de gestión que subyacen en la actividad de la correspondiente plataforma, a la naturaleza jurídica de sus titulares y a las operaciones llevadas a cabo. Son estos los tres ejes vertebradores del trabajo que se desarrolla en los siguientes apartados.

\section{Modelos de gestión}

La principal actividad desarrollada por las plataformas de financiación participativa consiste en poner en contacto a los promotores de proyectos que buscan financiación para llevarlos a cabo con personas que desean colaborar en el desarrollo de los mismos, sea mediante una ayuda económica, aportando ideas o cualquier otro medio dirigido a aquel fin. En este contexto, las plataformas prestan servicios diversos cuyo contenido esencial es la recepción de los proyectos, su valoración y selección, y el asesoramiento a los promotores en la configuración de la campaña, así como la publicación de los mismos en su página web, creando un entorno de confianza que permita canalizar las relaciones entre las partes intervinientes. A tal efecto, la práctica de la financiación participativa que llevan a cabo las plataformas de crowdfunding no lucrativo se articula a través de dos grandes modelos de gestión cuya distinción gira alrededor de dos elementos básicos: por un lado, la

2. Véase, en este sentido, Rodríguez de las Heras Ballell (2013, pág. 101)

3. En este mismo sentido, conviene destacar la inaplicación del reciente Reglamento (UE) 2020/1503, de 7 de octubre de 2020, del Parlamento y del Consejo, relativo a los proveedores europeos de servicios de financiación participativa para empresas, a las plataformas que actúan como intermediarias en el ámbito del crowdfunding no lucrativo, en la medida en que su objeto regulatorio es la armonización de las obligaciones y deberes de las plataformas que desarrollan servicios de financiación participativa consistentes en la concesión de préstamos y en la adquisición de valores negociables y otros instrumentos admitidos a tal efecto (ver, en este sentido, los considerandos $1,10,11$ y 13 y las definiciones contenidas en el art. 2 del citado reglamento). En consecuencia, las plataformas que son objeto de estudio en el presente trabajo no se hallan sujetas al régimen de autorizaciones y licencias previstas en la Ley 5/2015, de 27 de abril y, por ende, al citado reglamento comunitario. Véanse, en este mismo sentido, Camacho Clavijo (2018, págs. 31-58) y Moreno Serrano (2018, págs. 245-266). 
subjetividad de la plataforma, distinta o coincidente con la del propio perceptor de las cuantías inicialmente recaudadas, y, en segundo lugar, las funciones que la misma desempeña.

\subsection{Plataforma de financiación participativa que actúa como intermediaria}

Existe un primer modelo de gestión en el que la plataforma se encarga de publicitar el proyecto, canalizar las relaciones entre donante y beneficiario y gestionar los compromisos de aportaciones, así como las cuantías efectivamente donadas al proyecto, gestión que, en ocasiones, no es asumida por la plataforma, sino que es delegada en otras entidades, normalmente, financieras.

En este contexto, la plataforma tiene una subjetividad propia y diferenciada del perceptor de los fondos puesto que esta no es la destinataria de los mismos, sino que ejerce una función de intermediación. Así, la plataforma centra sus esfuerzos en poner en contacto a promotor y aportante $y$, una vez finalizada la campaña, activa la transacción económica que permite trasladar, directamente, los importes donados desde la cuenta del aportante a la cuenta del promotor del proyecto, cobrando a cambio un porcentaje de los mismos por la prestación de los correspondientes servicios. De este modo, se establece una relación jurídica bilateral entre la plataforma y el solicitante de fondos cuya naturaleza responde a la de un contrato de mediación o corretaje $^{4}$. En efecto, en estas operaciones existe un encargo en virtud del cual la plataforma se obliga con el promotor a publicitar su proyecto durante un período de tiempo determinado, utilizando la sede on line para facilitar el contacto entre los financiadores interesados en el proyecto y su promotor. En este sentido, la plataforma actúa como un intermediario en dicha relación y realiza las oportunas acciones para conseguir que las partes lleguen a un acuerdo que permita hacer efectiva la aportación al correspondiente proyecto ${ }^{5}$.

Por el desarrollo de esta función de intermediación, la plataforma cobrará la correspondiente comisión en concepto de retribución, pago que, con carácter general, correrá a cargo del promotor del proyecto.

\subsection{Plataforma de financiación participativa que actúa como gestora de los fondos}

En otras ocasiones, sin embargo, la plataforma no actúa como simple intermediaria, sino que resulta ser la responsable de la gestión de los fondos y, en primera instancia, la destinataria directa de los mismos. En este segundo modelo de gestión, la plataforma no tiene una subjetividad distinta y diferenciada al perceptor de las cuantías recaudadas en la medida en que los fondos son directamente ingresados por el benefactor en una cuenta corriente que es titularidad de la plataforma, existiendo, en consecuencia, una relación económica directa entre ambos.

Este esquema de funcionamiento tiene una especial incidencia en el ámbito del crowdfunding no lucrativo en el que las plataformas acostumbran a ser gestionadas por entidades sin ánimo de lucro. En concreto, existen supuestos en los que la entidad no lucrativa que gestiona la plataforma hace un llamamiento público para que otras entidades no lucrativas presenten sus proyectos. Tras un procedimiento de selección, la plataforma publicita los proyectos escogidos en su página web y los abre al público para la recaudación directa de los fondos, los cuales, en un momento ulterior al cierre de la campaña, son transferidos por la plataforma a la entidad promotora del proyecto. En estos supuestos existen dos operaciones diferenciadas: por un lado, la aportación inicial que efectúa el donante a la plataforma y, por otro, la posterior donación de las cuantías recaudadas por esta a la entidad promotora del proyecto. Este es el caso, por ejemplo, de las plataformas Goteo y Migranodearena, cuya gestión es realizada por las fundaciones Goteo y Real Dreams, respectivamente.

En este modelo de gestión existe, asimismo, un segundo modo de operar en el que la entidad sin ánimo de lucro, utilizando sus propios medios tecnológicos, pone en marcha una campaña para recaudar fondos para sus propios proyectos. Este es el caso de la Fundación del Museo Nacional de Arte de Cataluña, una entidad sin ánimo de lucro que periódicamente lanza campañas de apoyo al museo en aras de cumplir con el objetivo fundacional de la entidad de preservar y enriquecer sus fondos. También entra en esta modalidad la Fundación Junta constructora del Tem-

4. Véase, en este sentido, Gázquez Serrano (2007, págs. 181-216).

5. En este mismo sentido, Sanz Gómez y Lucas Durán (2015, pág. 25) y Soto Moya (2018, pág. 267). 
plo expiatorio de la Sagrada Familia o la Fundación de la Catedral de Santiago, entidades impulsoras de un plan de financiación que busca el apoyo de particulares, empresas e instituciones para garantizar el futuro de dichos templos y participar activamente en la conservación del patrimonio.

\section{Tributación de la plataforma en la imposición directa}

\subsection{Impuesto sobre sociedades}

Atendiendo a los dos modelos de gestión apuntados en el epígrafe anterior, en el presente apartado analizaremos la tributación de las plataformas de financiación participativa según desarrollen una simple función de intermediación o bien actúen como gestoras directas de los fondos por ser las destinatarias, iniciales o finales, de los mismos.

\subsubsection{Implicaciones fiscales para la plataforma que actúa como intermediaria}

Cuando la plataforma desarrolla una función de intermediación y cobra, por la correspondiente prestación de servicios, un porcentaje del importe recaudado al promotor del proyecto, tales ingresos deberán ser declarados como rendimientos de su actividad económica en cuanto está realizando una ordenación, por cuenta propia, de factores de producción y de recursos humanos, o de uno de ambos, con la finalidad de intervenir en la producción o distribución de bienes y servicios ${ }^{6}$.

En estos supuestos, la tributación de la plataforma se producirá en el ámbito del impuesto sobre sociedades siempre que se trate de entidades residentes en territorio español, debiendo declarar los beneficios obtenidos a nivel mundial por la diferencia entre los ingresos y los gastos de la actividad según las reglas de determinación de la base imponible establecidas en los arts. 10 y sigs. de la LIS. Asimismo, deberán tenerse en consideración las medidas para mitigar y evitar la doble imposición que, en su caso, se establezcan en los convenios de doble imposición correspondientes, así como las deducciones, bonificaciones o reducciones de tipos impositivos que puedan resultar de aplicación al caso concreto (por ejemplo, el tipo de gravamen reducido a entidades de nueva creación o los incentivos previstos para entidades de reducida dimensión).

Debemos destacar aquí que la práctica totalidad de las plataformas que, hasta el momento, se han constituido bajo este modelo de gestión basado en la simple intermediación, han optado por hacerlo como sociedades civiles o bien como sociedades de capital7. En ambos supuestos, las implicaciones fiscales serán las indicadas en los párrafos precedentes puesto que, desde el mes de enero de 2016, las sociedades civiles privadas que tengan actividad mercantil pasan de tributar en régimen de atribución de rentas a ser contribuyentes del impuesto sobre socieda$\operatorname{des}^{8} y$, en consecuencia, quedan sujetas a la presentación de la autoliquidación de dicho impuesto, así como al cumplimiento de las obligaciones formales correspondientes en términos equivalentes a los previstos para el resto de personas jurídicas?

De forma excepcional, existe alguna plataforma que, desarrollando este modelo de gestión, está constituida como fundación ${ }^{10}$. En este supuesto, si la entidad no lucrativa que gestiona la plataforma cobra una comisión por la presta-

6. Cfr. art. 5.1 de la Ley 27/2014, de 27 de noviembre, del Impuesto sobre Sociedades (en adelante LIS).

7. Así, por citar algunos ejemplos, Verkami es una sociedad civil privada, Ulule se ha constituido como una sociedad limitada unipersonal y Lánzanos como una sociedad limitada.

8. Véanse las disposiciones transitorias trigésima segunda y cuarta de la LIS.

9. La Dirección General de Tributos ha aclarado los requisitos que deben concurrir para que una sociedad civil sea considerada contribuyente a efectos del impuesto sobre sociedades. Así, por un lado, debe tener personalidad jurídica (véanse consultas V2378/15, de 28 de julio y V2394/15, de 28 de julio) y, por otro, debe tener objeto mercantil (véanse consultas V2391/15, de 28 de julio, V2394/15, de 28 de julio, V2430/15, de 30 de julio, y V2378/15, de 28 de julio). En consecuencia, entendemos que una sociedad civil titular de una plataforma de financiación participativa será sujeto pasivo del impuesto sobre sociedades en la medida en que está prestando servicios para el mercado en un ámbito propiamente mercantil.

10. Este es el caso de la Fundación Hazloposible. Esta entidad ofrece el entorno de la plataforma a las ONG para que publiciten sus proyectos y puedan recabar los fondos necesarios para llevarlos a cabo. Es importante destacar que, en estos supuestos, la entidad encargada de emitir los certificados de donaciones es la ONG destinataria final de los fondos, circunstancia que pone de relieve la simple función de intermediación que tiene la fundación gestora de la plataforma. 
ción del servicio, entendemos que tales cobros se realizan en el marco de una actividad económica y es en función de esta calificación que deberá procederse a analizar su tributación. En este contexto será preciso distinguir según se trate de una entidad que cumple los requisitos establecidos en el art. 3 de la Ley 49/2002, de 23 de diciembre (en adelante, LIFM), y haya optado por acogerse al régimen fiscal especial recogido en la misma, o bien se trate de una entidad no lucrativa que no cumple con dichos requisitos o que, cumpliéndolos, no haya optado por acogerse al citado régimen fiscal especial.

Pues bien, en el marco de la Ley 49/2002, es posible que los rendimientos derivados de las explotaciones económicas que llevan a cabo las entidades sin fines lucrativos titulares de la plataforma queden exentos de tributación en el impuesto sobre sociedades. A tal efecto, es preciso que en tales actividades concurran, simultáneamente, dos requisitos. Por un lado, es necesario que las actividades desarrolladas respondan a los fines u objeto de la entidad en la medida en que contribuyan a la satisfacción de los mismos. En este sentido, para que opere la exención resulta esencial que las actividades económicas Ilevadas a cabo en cumplimiento de los fines de la entidad se encuentren identificadas, con la mayor especificidad posible, entre las propias de la entidad no lucrativa en los correspondientes estatutos, constituyendo, de este modo, una presunción hominis de que son desarrolladas en el cumplimiento de su objeto fundacional'1.

Por otro, la aplicación de la exención requiere, además, que las actividades de las que proceden tales ingresos tengan cabida en el listado recogido en el art. 7 de la LIFM. Pues bien, si tenemos en cuenta que la comisión cobrada por la plataforma responde a la prestación de los servicios de publicación y mantenimiento del proyecto en la página web, a la tarea de captación de fondos y al asesoramiento al promotor del proyecto, nos encontramos ante rentas que proceden de actividades que no encajan en ninguno de los apartados del citado art. 7 de la LIFM. Esta circunstancia determina que, en principio, las rentas derivadas del cobro de las citadas comisiones se encuentren sujetas a tributación en el impuesto sobre sociedades a satisfacer por la plataforma gestionada por la entidad no lucrativa, debiendo integrarlas en la base imponible del impuesto y resultándoles de aplicación un tipo de gravamen del 10 por ciento (art. 10 de la LIFM).

La única posibilidad de que tales rentas queden exentas de tributación es por aplicación de las previsiones contenidas en los apartados 11 y 12 del citado art. 7 de la LIFM, en el sentido de que las explotaciones económicas de las que derivan las comisiones cobradas tengan carácter complementario o sean de escasa relevancia. Este carácter se determina atendiendo a su volumen, de modo que serán explotaciones económicas de carácter complementario aquellas cuyo importe neto de la cifra de negocios no supere el 20 por ciento de los ingresos totales de la entidad, o bien, por ser el importe neto de la cifra de negocios correspondiente a las mismas inferior a veinte mil euros, tengan la consideración de actividades de escasa relevancia. En este contexto debemos destacar que la elección de un porcentaje para determinar la exención de las explotaciones económicas auxiliares o complementarias tiene un importante inconveniente, a saber: la automática sujeción al impuesto de las rentas procedentes de dichas explotaciones cuando la actividad fundacional o estatutaria de la entidad no lucrativa gestora de la plataforma es desarroIlada de manera gratuita o bien mediante donativos. En tal caso, es evidente que en la práctica totalidad de supuestos el importe neto de la cifra de negocios correspondiente a tales actividades superará el 20 por ciento de los ingresos totales de la entidad puesto que entre tales ingresos solo se integrarán los procedentes de dichas actividades auxiliares o complementarias -en el caso de las plataformas, la comisión cobrada al promotor por la gestión de los proyectos-. Este grave inconveniente nos lleva a propugnar la necesidad de cambiar el mecanismo de determinación del carácter complementario o auxiliar de las explotaciones económicas de la entidad, apostando por un sistema que no tome en consideración un porcentaje de las rentas obtenidas o, en su caso, estableciendo una regla particular aplicable a los supuestos descritos.

En cualquier caso, la regulación actual exige el respeto de los límites indicados para que los ingresos obtenidos por la plataforma por la prestación del servicio de intermediación queden exentos de tributación, de modo que su exoneración dependerá de las circunstancias que concurran en cada caso concreto y en cada período impositivo.

11. Ver, en este sentido, Blázquez Lidoy y Martín Dégano (2012, pág. 306) 
Por otro lado, cuando la plataforma es gestionada por una entidad sin ánimo de lucro que no cumple los requisitos establecidos en la LIFM o que, cumpliéndolos, no se ha acogido al régimen fiscal especial previsto en la misma, será preciso atender al régimen de entidades parcialmente exentas previsto en los arts. 109 a 111 de la LIS. Pues bien, la aplicación conjunta de las previsiones contenidas en los arts. 110.1.a) y 110.2 de la LIS determina la exención de las rentas procedentes de la realización de actividades que constituyan el objeto social o finalidad específica de la entidad siempre y cuando no procedan de actividades económicas. En consecuencia, si tomamos en consideración el hecho de que la actividad que genera el cobro de las comisiones es, como hemos indicado al inicio del presente epígrafe, una actividad económica, las rentas derivadas de la misma siempre estarán sujetas a tributación en el impuesto sobre sociedades y tributarán al tipo general del 25 por ciento ${ }^{12}$

Debemos concluir, por tanto, que las comisiones cobradas por las plataformas gestionadas por entidades no lucrativas que llevan a cabo funciones de intermediación entre aportantes y promotores de proyectos quedan sujetas a tributación, con carácter general, en el impuesto sobre sociedades $y$, solo en el supuesto de entidades acogidas a la Ley 49/2002, podrían quedar exentas en el caso de tener la consideración de actividades complementarias o de escasa relevancia como consecuencia del reducido importe de las mismas respecto al volumen total de ingresos de la entidad no lucrativa titular de la plataforma.

\subsubsection{Implicaciones fiscales para la plataforma que actúa como gestora de los fondos recaudados}

A diferencia de los supuestos analizados en el epígrafe anterior, cuando la plataforma es titularidad de una entidad no lucrativa que no actúa como intermediaria sino como receptora inicial de fondos y gestora de los mismos, sus funciones en el marco de la campaña de financiación participativa no se desarrollan en el contexto de una actividad económica sino que la obtención de dichos fondos se articula a través de las donaciones realizadas por los diversos aportantes o colaboradores que se interesan por los proyectos de interés general que la misma promociona. Se convierte, así, en donataria principal de los mismos.

En este contexto, cabe preguntarse si la tributación de las cuantías recibidas por la entidad no lucrativa a modo de donación se encuentra sujetas a gravamen o bien resulta de aplicación algún tipo de exención. Para analizar esta cuestión es preciso distinguir según se trate de una entidad que cumple los requisitos establecidos en el art. 3 de la LIFM y haya optado por acogerse al régimen fiscal especial recogido en la misma, o bien se trate de una entidad no lucrativa que no cumple con dichos requisitos o que, cumpliéndolos, no haya optado por acogerse al citado régimen fiscal especial.

Pues bien, en el supuesto de entidades no lucrativas acogidas al régimen fiscal especial regulado en la LIFM, los fondos recaudados en el marco de una campaña de crowdfunding no lucrativo podrían quedar exentos por aplicación del art. 6.1.a) del citado texto normativo, de acuerdo con el cual están exentos de tributación en el impuesto sobre sociedades «los donativos y donaciones recibidos para colaborar con los fines de la entidad». La premisa necesaria para entender que se cumple este requisito es que los fines que se van a ver satisfechos con los proyectos financiados estén relacionados con los fines de la entidad no lucrativa receptora de los fondos. Asimismo, para dar mayor seguridad jurídica a la operación, sería adecuado que la captación de fondos para su distribución entre proyectos de otras organizaciones conste en los estatutos de la entidad no lucrativa titular de la plataforma como una de las actividades a través de las que se va a desarrollar el fin fundacional u objeto de la misma. Para reforzar esta idea, debemos destacar que en el justificante que la entidad no lucrativa debe entregar a los donantes para la deducibilidad del donativo en su respectivo impuesto personal, debe constar el destino que la entidad donataria dará al objeto de la donación «en el cumplimiento de su finalidad específica». Entendemos, así, que la vinculación entre la donación recibida y la colaboración con los fines de la entidad queda suficientemente garantizada $y$, por

12. Confirman esta consideración las contestaciones a consultas de la DGT V0022/2005, de 28 de enero, V0216/2005, de 14 de junio, V0025/2008, de 9 de enero, V1787/2009, de 31 de julio, V1795/16, de 22 de abril, y V4317/16, de 6 de octubre, así como las SSTS de 26 de febrero de 1993, 1 de octubre de 1993 y 17 de febrero de 2010 
tanto, los ingresos que la entidad no lucrativa recibe por este concepto no deben tributar por aplicación de la exención prevista en el art. 6.1.a) de la LIFM ${ }^{13}$.

Cuestión distinta pero que consideramos oportuno traer a colación, es la posibilidad de que la entidad no lucrativa que recauda fondos y los distribuye a terceras entidades no lucrativas que también cumplen los requisitos de la Ley 49/2002 pueda aplicar los beneficios fiscales establecidos en dicha ley para las actuaciones de mecenazgo. Este sería el caso, por ejemplo, de una plataforma gestionada por una fundación que, tras recaudar los fondos, efectúa una donación a diversas entidades no lucrativas para el desarrollo de sus respectivos proyectos. En este supuesto entendemos que esta donación no sería susceptible de deducción en la cuota de la fundación que ha recaudado los fondos puesto que, en realidad, estaría realizando una aplicación de rentas en cumplimiento de su objeto o finalidad específica y no una donación, sin olvidar que, además, se estaría produciendo una acumulación de beneficios fiscales cuyo origen responde a unas mismas cuantías.

Por otro lado, cuando la plataforma es gestionada por una entidad sin ánimo de lucro que no cumple los requisitos establecidos en la LIFM o que, cumpliéndolos, no se ha acogido al régimen fiscal especial previsto en la misma, la tributación que corresponde aplicar a los fondos recibidos en el contexto de una campaña de crowdfunding debe ser dilucidada en atención a las previsiones contenidas en el art. 110.1.b) de la LIS. De acuerdo con este precepto, las rentas derivadas de adquisiciones a título gratuito están exentas de tributación siempre que se obtengan en cumplimiento de su objeto o finalidad específica. En este contexto, debemos entender que las donaciones recibidas en una campaña de crowdfunding, en cuanto rentas derivadas de adquisiciones a título gratuito, quedarán exentas de tributación siempre y cuando en los estatutos de la entidad beneficiaria quede claro que su objeto o finalidad específica consiste en la captación de fondos a través de plataformas en internet para financiar proyectos de interés general. Esta afirmación, meridianamente clara en relación con las aportaciones dinerarias, puede plantear ciertas dificultades cuando la donación se materializa mediante la entrega de un bien. Esta posibilidad, aunque reducida en la práctica actual, sí que se contempla en algunas de las plataformas de crowdfunding existentes en la actualidad ${ }^{14}$. En tales supuestos, será preciso que el bien donado contribuya al cumplimiento de los fines de la entidad para que dicha donación quede exenta de tributación, de modo que se requerirá la afectación directa de los bienes adquiridos por donación al desarrollo de las actividades que la entidad no lucrativa lleva a cabo para la satisfacción de sus fines ${ }^{15}$.

Para cerrar el círculo de las implicaciones fiscales que las acciones de crowdfunding tienen para la entidad no lucrativa receptora de los fondos, es preciso tener en cuenta que, una vez finalizada la campaña, dicha entidad realiza una donación de los fondos recaudados a las entidades a quienes corresponden los proyectos previamente seleccionados. En este contexto, la entidad no lucrativa gestora de la plataforma acostumbra a cobrar al promotor del proyecto un porcentaje de las cuantías recaudadas, cobro que se efectúa en concepto de mantenimiento de dicho proyecto en la plataforma y cuyos importes son invertidos en mejoras tecnológicas y en la promoción y gestión de la plataforma. A nuestro juicio, estos cobros se realizan en el marco de una actividad económica desarrollada por la entidad no lucrativa y es en función de esta calificación que deberá tributar. En este contexto, debemos trasladar aquí las consideraciones realizadas en el epígrafe anterior relativas a la tributación de los ingresos obtenidos por entidades no lucrativas en el desarrollo de explotaciones económicas, de modo que, con carácter general, las comisiones cobradas al promotor del proyecto quedarán sujetas a tributación en el ámbito del impuesto sobre sociedades a satisfacer por la entidad no lucrativa titular de la plataforma, con independencia de que esté o no acogida al régimen fiscal especial de la Ley 49/200216.

\footnotetext{
13. Esta interpretación, que había sido vetada por la Administración tributaria en numerosas consultas vinculantes, ha sido finalmente validada por la Audiencia Nacional en sentencia de 1 de octubre de 2015 y confirmada por el TEAC en Resolución de 8 de septiembre de 2016.

14. Este es el caso, por ejemplo, de la Fundación de Real Dreams en el marco del programa Donalo.org.

15. En esta misma línea se pronuncian Blázquez Lidoy y Martín Dégano (2012, pág. 422).

16. En este mismo sentido, véase Lucas Durán (2017a, pág. 203).
} 


\subsection{Tributación en el impuesto sobre la renta de no residentes}

Cuando la plataforma de financiación participativa es residente fiscal en otro país pero tiene en España un establecimiento permanente al que atribuye los rendimientos generados en territorio español, la plataforma deberá tributar en el ámbito del impuesto sobre la renta de no residentes (en adelante, IRNR) por los beneficios obtenidos en España mediante dicho establecimiento permanente ${ }^{17}$, sin perjuicio de lo que puedan establecer los convenios de doble imposición. Asimismo, si la plataforma no dispone de establecimiento permanente alguno en territorio español, también deberá tributar en el IRNR pero únicamente, y de forma puntual, por las rentas obtenidas en dicho territorio siempre que, por aplicación de las reglas previstas en el art. 13.b) del Real Decreto Legislativo 5/2004, de 5 de marzo, por el que se aprueba el Texto Refundido de la Ley del Impuesto sobre la Renta de No Residentes (en lo sucesivo, TRLIRNR), pueda entenderse que la renta ha sido obtenida en territorio españoli8.

En el contexto descrito, el problema que se plantea en relación con nuestro objeto de estudio consiste en determinar cuándo cabe entender que una plataforma de financiación participativa tiene un establecimiento permanente en territorio español en la medida en que su actividad es íntegramente desempeñada a través de internet $y$, en consecuencia, sin presencia física alguna en el país o países en los que se efectúa la efectiva recaudación de fondos derivados de la campaña de financiación en masa ${ }^{19}$. A tal efecto, resulta relevante el contenido del art. 5 del Modelo de Convenio de la OCDE, de acuerdo con el cual en estos supuestos se deberá atender al lugar en el que está ubicado el servidor físico que almacena las aplicaciones y datos electrónicos de la plataforma siempre y cuando dicha localización se produzca durante un «período de tiempo lo suficientemente amplio para considerarse fijo». En este contexto, deberán ser los Estados contratantes los que fijen los límites temporales de este requisito, tanto en los convenios de doble imposición como en la correspondiente normativa interna ${ }^{20}$.

La complejidad de la cuestión se ha visto acrecentada con la introducción, tras la publicación de la propuesta de Directiva del Consejo COM/2018/0147 el día 21 de marzo de 2018, del concepto de la denominada «presencia digital significativa», un concepto que viene delimitado por tres elementos esenciales -el volumen de ingresos, el número de usuarios y el de contratos de la correspondiente actividad- cuya concreta definición y delimitación no está exenta de problemas²1. A esta dificultad se añade, también, la compleja tarea de renegociar los numerosos convenios de doble imposición firmados por España con el objeto de incorporar dichas previsiones en aras a identificar el territorio en el que quedarán sujetas las rentas obtenidas por las plataformas de financiación participativa. Ante esta indefinición, creemos que se abre una nueva brecha que dará lugar a numerosos conflictos entre la Administración tributaria y los contribuyentes y deberemos esperar la respuesta de los tribunales de justicia. No podemos más que propugnar la necesidad de una redefinición del concepto de establecimiento permanente adaptado a las plataformas de financiación participativa, así como una regulación específica en la materia que implique a todos los Estados y permita dar una mayor seguridad jurídica a los operadores de las campañas de financiación en masa.

\section{Tributación de la plataforma en el ámbito de la imposición indirecta}

\subsection{Implicaciones fiscales para la plataforma que actúa como intermediaria}

Como hemos visto, cuando la función de la plataforma se limita a poner en contacto al promotor del proyecto y

17. Sobre la determinación de la cuota tributaria en estos supuestos véanse los arts. 16 a 19 del Real Decreto Legislativo $5 / 2004$, de 5 de marzo, por el que se aprueba el Texto Refundido de la Ley del Impuesto sobre la Renta de No Residentes y, por remisión, el capítulo XIV de la LIS.

18. En estos supuestos, la cuota tributaria se determina operación por operación, atendiendo a la naturaleza de la renta obtenida. Sobre la determinación de la base imponible y la cuota tributaria, véanse los arts. 24 y 25 del TRLIRNR.

19. Sobre el concepto tradicional de establecimiento permanente y los problemas derivados de la economía digital véase Cruz Padial y Sánchez-Archidona (2017, pág. 68).

20.Así, por ejemplo, el art. 13.1.a) del TRLIRNR establece un período mínimo de seis meses para considerar que una entidad dispone de un establecimiento permanente en territorio español.

21. Sobre esta cuestión véase por todos Belda (2021, págs. 1-13). 
al aportante, los servicios de mediación que lleva a cabo son remunerados mediante la correspondiente comisión. En este contexto, dichos ingresos quedarán sujetos al impuesto sobre el valor añadido (en lo sucesivo, IVA) en la medida en que puedan ser considerados prestaciones de servicios realizadas en el ámbito espacial del impuesto por empresarios o profesionales a título oneroso, con carácter habitual u ocasional, en el desarrollo de dicha actividad ${ }^{22}$.

Respecto a la condición de empresario o profesional de la plataforma, no cabe duda, como ya hemos tenido ocasión de apuntar anteriormente, de que la entidad gestora de la misma tiene dicha consideración en la medida en que realiza una «ordenación por cuenta propia de factores de producción materiales y humanos o de uno de ellos, con la finalidad de intervenir en la producción o distribución de bienes o servicios» (art. 5.Dos de la LIVA). Asimismo, la actividad de intermediación que lleva a cabo la plataforma resulta remunerada mediante la correspondiente comisión, convirtiéndose, así, en contraprestación del servicio prestado por vía electrónica y otorgándole, en consecuencia, el carácter oneroso exigido por la normativa para determinar su sujeción al impuesto indirecto. Podemos afirmar, así, que las comisiones percibidas por la entidad gestora de la plataforma constituyen la contraprestación por la prestación de servicios por vía electrónica y que, como tales, quedarán sujetas al IVA ${ }^{23}$. Sin embargo, para que dicha sujeción se produzca es preciso que la prestación de tales servicios haya sido efectuada en el ámbito espacial del impuesto, para cuya determinación será preciso acudir a las reglas de localización contempladas en los arts. 69 y 70 de la LIVA.

En este contexto, la prestación de servicios se entiende realizada en territorio español y, por tanto, está sujeta al impuesto, cuando el destinatario de los servicios sea un empresario o profesional que actúe como tal y radique en el territorio de aplicación del impuesto la sede de su actividad económica, o tenga en el mismo un establecimiento permanente 0 , en su defecto, el lugar de su domicilio o residencia habitual. A tal efecto, se requiere, además, que se trate de servicios que tengan por destinatarios a dicha sede, establecimiento permanente, domicilio o residencia habitual, con independencia de dónde se encuentre establecido el prestador de los servicios y el lugar desde el que los preste.

Asimismo, los servicios prestados por vía electrónica se entienden realizados en el territorio de aplicación del impuesto cuando el destinatario de los mismos sea un particular que esté establecido o tenga su residencia habitual en dicho territorio, supuesto en el que la plataforma deberá repercutirle el IVA al tipo impositivo español. Asimismo, a sensu contrario, no se entienden realizados en el territorio de aplicación del impuesto los servicios prestados por una plataforma de crowdfunding establecida en territorio español cuando los destinatarios de sus servicios sean particulares residentes en otros países de la Unión Europea o de terceros países.

\subsection{Implicaciones fiscales para la plataforma que actúa como gestora de los fondos recaudados}

Cuando la plataforma actúa como gestora de los fondos recaudados resulta ser la receptora inicial de los mismos y, en su caso, procede a trasladar dichos importes al promotor del correspondiente proyecto una vez finalizada la campaña. En tales supuestos resultará de aplicación la exención establecida en el art. 20.Uno.18 de la LIVA en la medida en que la operación financiera que subyace en dicha operación es la que corresponde a un depósito en efectivo en sus diversas formas o a los servicios de cobro y pago prestados por el depositario a favor del depositante ${ }^{24}$

\section{Conclusiones}

La Ley 5/2015, de 27 de abril, de fomento de la financiación empresarial, excluye de su ámbito de aplicación a las plataformas de financiación colectiva que, aun poniendo en contacto de forma profesional y mediante medios tecnológicos o digitales a aportantes y promotores de proyectos, capten sus recursos mediante donaciones, ventas de bienes y servicios o préstamos sin interés, es decir, aquellas plataformas cuya actividad se centre en la cap-

22. Cfr. art. 4.Uno de la Ley 37/1992, de 28 de diciembre, del Impuesto sobre el Valor Añadido (en lo sucesivo, LIVA).

23. Véase en este sentido la consulta de la DGT V1811/16, de 25 de abril.

24. Véase al respecto la consulta de la DGT V2895/16, de 22 de junio. 
tación de fondos mediante operaciones de naturaleza no financiera. En este contexto, la identificación del régimen fiscal que corresponde aplicar a tales plataformas y sus obligaciones tributarias requiere un análisis pormenorizado de los modelos de gestión que subyacen en la actividad de las mismas, de la naturaleza jurídica de sus titulares y de las operaciones llevadas a cabo, extremos que han constituido los ejes conductores del presente trabajo.

La observación y estudio de las plataformas de financiación participativa de carácter no lucrativo creadas hasta el momento nos han permito identificar dos modelos de organización distintos tomando en consideración dos aspectos esenciales: por un lado, la subjetividad de la plataforma, que puede ser distinta o coincidente con la del perceptor de las cuantías recaudadas, y, por otro, la función intermediadora o bien gestora que lleva a cabo la plataforma en la recaudación y aplicación de dichas cuantías.

En los supuestos en que la plataforma actúa como intermediaria, hemos podido constatar su plena sujeción al impuesto sobre sociedades, sea cual sea la forma jurídica adoptada en su constitución. Mención especial cabe realizar de las plataformas gestionadas por entidades no lucrativas acogidas a la Ley 49/2002, de 23 de diciembre. En tales supuestos, a pesar de que los ingresos obtenidos por la prestación del servicio de intermediación deriven del ejercicio de una explotación económica recogida entre sus fines fundacionales, no resultará aplicable exención alguna puesto que tal actividad no tiene cabida en el listado recogido en el art. 7 de la LIFM. Esta exclusión, que a priori podría considerarse cuestionable por la propia naturaleza de la entidad gestora de la plataforma, tiene una clara justificación jurídica puesto que la actividad de intermediación de la que provienen los ingresos cuya exención se plantea nada tiene que ver con los fines de interés general de la entidad. La única salvedad a esta afirmación debe efectuarse en relación con las actividades que puedan ser calificadas como complementarias o de escasa relevancia por no superar determinados límites porcentuales o cuantitativos, respectivamente. La aplicación práctica de esta exención plantea algunos problemas puesto que requiere un análisis casuístico de las circunstancias que concurren en cada caso y en cada período impositivo y exigen una adecuada planificación y estricto control de los ingresos obtenidos por la plataforma mediante la actividad de intermediación relativa al volumen total de ingresos de la entidad. En este contexto, es aconsejable cambiar la configuración de la exención en aras de otorgar una mayor seguridad jurídica a la plataforma, apostando por un sistema que no tome en consideración un porcentaje de las rentas obtenidas 0 , en su caso, estableciendo una regla particular aplicable a los supuestos descritos.

Cuando la plataforma actúa como destinaria inicial de los fondos y gestora de los mismos hemos podido constatar que su forma jurídica es siempre la de una entidad sin ánimo de lucro. En tal caso, y a diferencia de los supuestos de intermediación, la contabilización de las cuantías recaudadas no debe realizarse en el contexto de una explotación económica sino como donativos o donaciones recibidos para colaborar con los fines propios de la entidad. Esta circunstancia permitirá excluir de gravamen tales rentas, sea por aplicación del art. 6.1.a) de la LIFM o bien del art. 110.1.b) de la LIS, según las entidades no lucrativas titulares de la plataforma estén o no acogidas al régimen fiscal especial contenido en la LIFM. Para la aplicación de la exención resulta de especial relevancia la redacción de los estatutos de la entidad, en los que es imprescindible que aparezca claramente identificada, entre sus fines u objeto, la captación de fondos para la financiación de proyectos propios o desarrollados por otras entidades no lucrativas, ya que de otro modo la Administración tributaria entrará a cuestionar la viabilidad de la exención. A nuestro juicio, esta exigencia resulta coherente con los principios constitucionales tributarios puesto que es preciso garantizar que la entidad gestora de la plataforma que aplica la exención lleva a cabo actividades de interés general y, precisamente por este motivo, las cuantías recaudadas quedan exoneradas de gravamen pues repercutirán en beneficio de la colectividad.

Uno de los mayores problemas que plantea la fiscalidad de las plataformas en el ámbito de la imposición directa se produce cuando dichas plataformas no son residentes en territorio español y no disponen en nuestro país de un establecimiento permanente en el sentido tradicional del concepto. En tales supuestos, la aplicación de las normas que rigen la fiscalidad internacional determinará, en virtud de los correspondientes convenios de doble imposición, que las rentas obtenidas por las plataformas no tributen en España con la consecuente pérdida de ingresos fiscales para la Hacienda española. Para paliar esta situación sugerimos la renegociación 
de los convenios para evitar la doble imposición y, de manera urgente, aquellos que España haya firmado con los países en los que acostumbran a situar su residencia fiscal las plataformas de financiación participativa. En esta renegociación debería prestarse especial atención a la redefinición del concepto de establecimiento permanente y su vinculación al lugar en el que existe una «presencia digital significativa», para lo cual podría atenderse a parámetros diversos tales como el volumen de ingresos o el número de usuarios.
Finalmente, por lo que se refiere a la imposición indirecta, no existen aspectos destacables. Así, con carácter general, la tributación de la plataforma que actúa como intermediaria se producirá en territorio español de acuerdo con las reglas de localización previstas en nuestra legislación. Asimismo, cuando la plataforma actúe como gestora directa de los fondos, las operaciones realizadas en el contexto de la campaña de financiación participativa quedarán exentas de tributación por aplicación del art. 20.Uno.18 de la LIVA. 


\section{Referencias bibliográficas}

BELDA, I. (2021). «Els conceptes tributaris de l'establiment permanent i els punts de connexió en relació amb l'adveniment d'Internet of Things». IDP. Revista d'Internet, Dret i Política, núm. 32, págs. 1-13 [en línea] DOI: https://doi.org/10.7238/idp.v0i32.3209 [Fecha de consulta: 2 de marzo de 2021].

BLÁZQUEZ LIDOY, A.; MARTÍN DÉGANO, I. (2012). Manual tributario de entidades no lucrativas (asociaciones y fundaciones). Madrid: Ed. CEF.

CAMACHO CLAVIJO, S. (2018). «Las modalidades de financiación participativa o crowdfunding y su distinción respecto de figuras afines: equity-crowdfunding emisión de valores y obligaciones, crowdlending y mecenazgo participativo». En: MARTÍNEZ-ECHEVARRÍA, A.; PAÑEDA USUNÁRIZ, F. (dirs.). Las plataformas de financiación participativa -crowdfunding-. Navarra: Thomson ReutersAranzadi, págs. 31-58.

CRUZ PADIAL, I.; SÁNCHEZ-ARCHIDONA, G. (2017). «Economía digital, establecimiento permanente y presencia digital significativa: tras las conclusiones del informe del GEFED». Quincena Fiscal, núm. 18, págs. 59-88 [en línea] https://www.researchgate.net/publication/326772913_ECONOMIA_DIGITAL_ESTABLECIMIENTO_PERMANENTE_Y_PRESENCIA_DIGITAL_SIGNIFICATIVA_TRAS_LAS_ CONCLUSIONES_DEL_INFORME_DEL_GEFED [Fecha de consulta: 2 de marzo de 2021].

FERNÁNDEZ AMOR, J. A. (2018). «Efectos de un principio de justicia tributaria universal: evolución del establecimiento permanente a la presencia digital significativa en el marco de la economía colaborativa y social». En: PEDREIRA MENÉNDEZ, J. (dir.); PASCUAL GONZÁLEZ, M. (coord.). Fiscalidad de la colaboración social. Navarra: Thomson Reuters-Aranzadi, págs. 151-180.

GÁZQUEZ SERRANO, L. (2007). El contrato de mediación o corretaje. Madrid: La Ley.

LUCAS DURÁN, M. (2017a). «El crowdfunding como vía de protección del Patrimonio Histórico: aspectos tributarios». En: ÁLVAREZ ARROYO, F. (dir.); CEBRIÁ GARCÍA, M. D. (coord.). Haciendas Locales y Patrimonio Histórico y cultural. España: Dykinson, págs. 185-236.

LUCAS DURÁN, M. (2017b). «Problemática jurídica de la economía colaborativa: especial referencia a la fiscalidad de las plataformas». Anuario de la Facultad de Derecho. Universidad de Alcalá-Dykinson, págs. 131-172.

MANCHANCOSES GARCÍA, E. (2019). «Las plataformas digitales: protagonistas actuales del Derecho tributario». En: AGUACIL MARÍ, M. P. (dir).; MONTESINOS OLTRA, S. (coord.). Aspectos jurídicos y fiscales de la economía colaborativa. Valencia: Tirant lo Blanch, págs. 175-214.

MORENO SERRANO, E. (2018). «Cuestiones jurídicas derivadas de la aplicación del crowdfunding». En: MARTÍNEZ-ECHEVARRÍA, A.; PAÑEDA USUNÁRIZ, F. (dirs.). Las plataformas de financiación participativa -crowdfunding-. Navarra: Thomson Reuters-Aranzadi, págs. 245-266.

RODRÍGUEZ DE LAS HERAS BALLELL, T. (2013). El crowdfunding: una forma de financiación colectiva, colaborativa y participativa de proyectos. Pensar en Derecho, núm. 3, págs. 101-123 [en línea] http:// www.derecho.uba.ar/publicaciones/pensar-en-derecho/revistas/3/el-crowdfunding-una-forma-de-financiacioncolectiva-colaborativa-y-participativa-de-proyectos.pdf [Fecha de consulta: 2 de marzo de 2021].

RODRÍGUEZ MARTÍNEZ, I. (2017). «EI servicio de mediación electrónica y las plataformas de economía colaborativa». Revista de Derecho Mercantil, núm. 305, págs. 181-216.

SANZ GÓMEZ, R. J.; LUCAS DURÁN, M. (2015). «Implicaciones tributarias del crowdfunding o financiación colectiva». Quincena Fiscal, núm. 9, págs. 19-69 [en línea] https://www.researchgate.net/ publication/309308870_Implicaciones_tributarias_del_crowdfunding_o_financiacion_colectiva [Fecha de consulta: 2 de marzo de 2021].

SOTO MOYA, M. M. (2018). Tributación del crowdfunding. Valencia: Tirant lo Blanch. 


\title{
Cita recomendada
}

CASANELLAS CHUECOS, Montserrat (2021). «Tributación de las plataformas de financiación participativa no financiera». IDP. Revista de Internet, Derecho y Política, núm. 33 (octubre). UOC [Fecha de consulta: dd/mm/aa] http://dx.doi.org/10.7238/idp.v0i33.377821

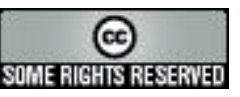

\begin{abstract}
Los textos publicados en esta revista están -si no se indica lo contrario- bajo una licencia Reconocimiento-Sin obras derivadas 3.0 España de Creative Commons. Puede copiarlos, distribuirlos y comunicarlos públicamente siempre que cite su autor y la revista y la institución que los publica (IDP. Revista de Internet, Derecho y Política; UOC); no haga con ellos obras derivadas. La licencia completa se puede consultar en: http://creativecommons.org/ licenses/by-nd/3.0/es/deed.es.
\end{abstract}

\section{Sobre la autora}

Montserrat Casanellas Chuecos

Profesora agregada del área de Derecho Financiero y Tributario, Facultad de Derecho. Universidad de Barcelona.

Ha impartido docencia en los grados en Derecho, Gestión y Administración Pública y Relaciones Laborales, y en los másteres oficiales de Gestión Cultural, Derecho de la Empresa y los Negocios y Abogacía.

Ha desarrollado diversos cargos y encargos de gestión académica. Entre otros, ha sido coordinadora del máster oficial de Gestoría Administrativa, coordinadora del máster oficial de la Abogacía, directora de la Escuela de Másteres y Posgrados y, actualmente, vicedecana de Relaciones Institucionales, Patrocinio y Posgrados.

Su actividad investigadora ha estado centrada en la tributación de las entidades sin ánimo de lucro y el mecenazgo, así como en las medidas de simplificación de la tributación de las rentas empresariales. En este contexto, ha sido miembro de varios Proyectos I+D financiados por el Ministerio de Economía y Competitividad y la AECID. Actualmente, forma parte del Grupo de Investigación Consolidado por la Generalitat de Cataluña «Derecho Tributario y Política Fiscal».

Ha sido profesora visitante de la Universidad de Verona (Italia) y ha realizado diversas estancias de investigación en Brasil, Venezuela e Italia.

Asimismo, en el ámbito docente, es autora de varios manuales de derecho financiero y tributario y artículos sobre competencias transversales y actividades de aprendizaje por competencias. 